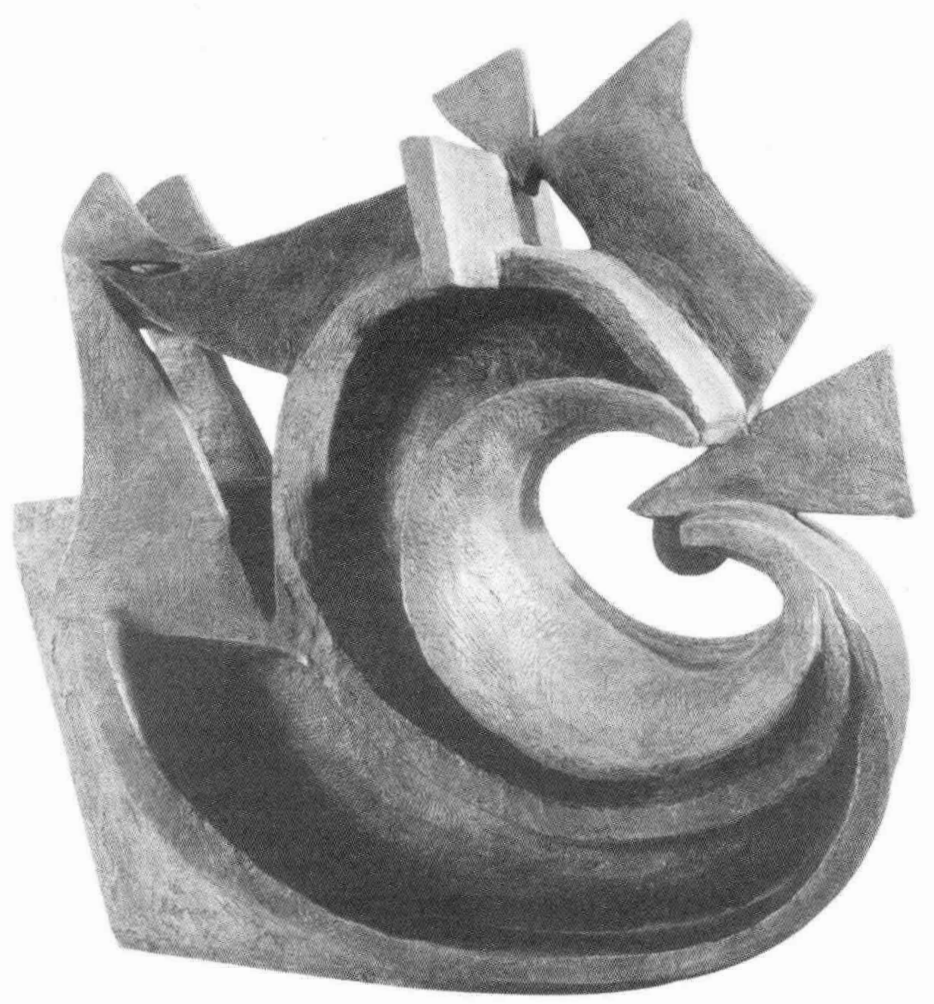




\section{Angel Herrerín López}

Doctor en Historia por la Universidad Nacional de Educación a Distancia (UNED). Su línea de investigación se ha centrado en el exilio republicano de 1939, el anarquismo y el periodo franquista. Ha publicado más de una docena de artículos entre revistas especializadas y colaboraciones en libros. Cabe destacar su monografía La CNT durante el franquismo. Clandestinidad y exilio (1939-1975), Madrid, 2004. En la actualidad está preparando un libro, en colaboración con el doctor Abdón Mateos, sobre la actuación de la Junta de Auxilio a los Republicanos Españoles (JARE) en México.

\section{Resumen}

El presente artículo analiza, por un lado, el volumen de los exiliados republicanos españoles que llegaron a Santo Domingo desde el fin de la guerra civil española, su ubicación en la isla y las dificultades a las que tuvieron que hacer frente para encontrar una ocupación, lo suficientemente estable, que les permitiera reemprender una nueva vida. Por otro, se analiza la ayuda que estos refugiados recibieron por parte de las organizaciones constituidas por los españoles exiliados. En primer lugar, por el Servicio de Evacuación de los Republicanos Españoles (SERE), que costeó el transporte desde Europa, y, seguidamente, por la Junta de Auxilio a los Republicanos Españoles (JARE), que, desde mediados de 1940, les ayudó en su estancia en la isla y colaboró en su salida hacia otro destino mejor.

Palabras clave:

Exilio, Santo Domingo, SERE, JARE.

\section{Abstract}

This article analyzes the group of Spanish Republic exiles that arrived in Santo Domingo after the end of the Spanish Civil War, their location in the island and the difficulties they faced in finding sufficiently stable jobs to be able to begin a new life. It also analyzes the help that these refugees received from the organizations created by Spanish exiles, first from the Spanish Republican Evacuation Service (SERE) which paid for their transport from Europe and immediately afterwards, by the Board of Assistance for Spanish Republicans (JARE), which, from the mid 1940 s onwards, assisted them with their stay on the island and helped them find more suitable destinations.

Key words:

Exile, Santo Domingo, SERE, JARE.

Fecha de recepción: noviembre de 2004

Fecha de aceptación: febrero de 2005 


\title{
La ayuda a los republicanos españoles exiliados en Santo Domingo*
}

\author{
Ángel Herrerín López
}

\section{$\mathrm{L}$}

os españoles que habían perdido la guerra civil, y que tomaron el camino del exilio, seguramente no imaginaban la odisea a la que iban a tener que enfrentarse desde el mismo momento en que traspasaron los límites de nuestras fronteras.

La humillante acogida de la que fueron objeto en Francia, y su internamiento en campos de concentración que no reunían las mínimas condiciones de salubridad, iban a ser las dos primeras desventuras de una larga lista a la que tuvieron que hacer frente. El estallido de la segunda guerra mundial, la ocupación alemana de Francia, el peligro de las extradiciones a la España de Franco o las deportaciones a los campos de exterminio nazi fueron otros tantos episodios trágicos en el inicio de su exilio.

Con esta situación de fondo, no es de extrañar que la posibilidad de desplazarse al continente americano significara, en la mayoría de los casos, la mejor salida posible. El paso del tiempo ha dado la razón a esta opción, y el exilio en México ha llegado a ser considerado como un exilio privilegiado, en gran medida por las impor-

* Este artículo ha sido realizado dentro del proyecto de investigación subvencionado por la UNED titulado: La Ayuda a los Exiliados Españoles de la Guerra Civil. tantes posibilidades de ascenso social que los españoles encontraron en esas tierras.

Pero hubo una parte de los refugiados españoles que recalaron en otros países americanos en los que las condiciones de vida del lugar y las posibilidades de promoción social no fueron tan satisfactorias. En concreto, hay que referirse a los exiliados que tuvieron como destino República Dominicana. La satisfacción por la acogida de la que fueron objeto por las autoridades dominicanas se tornó en desilusión y necesidad imperiosa de abandonar el país ante las duras condiciones de vida que imponía el país caribeño.

La llegada de los exiliados españoles a la isla estuvo organizada por el Servicio de Evacuación de los Republicanos Españoles (SERE). Sin embargo, ya a mediados de 1940 el organismo de ayuda que había puesto en marcha Negrín carecía de fondos para el mantenimiento de los refugiados.

Desde este momento, la Junta de Auxilio a los Republicanos Españoles (JARE), cuya delegación en México estaba dirigida por Indalecio Prieto, asumió la responsabilidad sobre las condiciones en que se desenvolvieron los refugiados que allí habían recalado.

El presente artículo trata de analizar tanto las condiciones de vida de los refugiados españoles en República Domini- 
cana, como la actuación que la JARE puso en marcha para mejorar la situación de los españoles allí exiliados. Por un lado, a través de servicios comunitarios y subvenciones o subsidios personales $y$, por otro, con la política de embarques, que permitió la salida de la isla a un buen número de exiliados hacia otros países americanos donde las posibilidades fueran mayores.

\section{EL VOLUMEN DEL EXILIO EN REPÚBLICA DOMINICANA}

República Dominicana fue el país americano que después de México admitió a un mayor número de exiliados. En líneas generales, a México fueron a parar algo más de 20000 españoles. En el resto del continente las cifras fueron mucho más modestas. Así, en países como Venezuela o Argentina fueron admitidos, entre ambos, 6000 refugiados, en Chile recalaron algo más de 2000 españoles, mientras que las cifras para países como Ecuador, Perú o Panamá solamente alcanzaron varias decenas. $^{1}$

En cuanto a República Dominicana, las cifras de españoles en el momento de mayor presencia -que correspondió a mediados de 1940- oscilaron entre los 3000 y los 4000 refugiados. Esta cantidad es todavía más representativa si se tiene en cuenta que la población de este país, en ese momento, era inferior a $2000000, y$ el número de habitantes en su capital no alcanzaba los $100000 .^{2}$

' Sobre el exilio republicano de 1939, véase Lida, Inmigración, 1994 e Inmigración, 1997; Pla, Exilians, 1999; Rubio, Emigración, 1977; Llorens, Exilio, 1976, y Gibaja, Indalecio, 1995.

${ }^{2}$ Sobre el exilio en República Dominicana véase Llorens, Memorias, 1975.
Por otro lado, hay que tener en cuenta que la economía de República Dominicana era muy deficiente. Las principales actividades de los dominicanos eran la agricultura y la ganadería. Era una auténtica agricultura de subsistencia, con cultivos como las papas, el maní o las habichuelas. La producción agrícola se empleaba, casi en su totalidad, para el mantenimiento de la población que, como es fácil de imaginar, vivía en medio de una gran miseria. La industria era prácticamente inexistente, salvo la azucarera, que se encontraba en manos de empresas extranjeras. En cuanto al comercio, los antiguos residentes españoles y los siriolibaneses lo monopolizaban. Políticamente, República Dominicana estaba en manos del dictador Trujillo, quien dirigía con mano de hierro los destinos de su país.

Cabe preguntarse cómo un país con estas condiciones sociales, económicas y políticas admitió un número tan abultado de refugiados. A este respecto, conviene insistir en que ningún país americano dio asilo a tantos españoles si tenemos en cuenta la proporción existente entre población y refugiados. Según Vicente Llorens, la respuesta hay que buscarla en que el dictador quiso lavar viejas culpas, en concreto, la matanza de haitianos en 1937. También hay que tener en cuenta los planes increibles de Trujillo en cuanto al incremento demográfico o el blanqueo de la raza. Sin olvidar, a mi modo de ver, las posibilidades de desarrollo económico que para República Dominicana podían suponer la entrada en el país de mano de obra cualificada y las posibles inversiones de las organizaciones de ayuda españolas. ${ }^{3}$ p. 96

${ }^{3}$ Véanse ibid., pp. 94-95, y Pla, Exilians, 1999, 
La primera dificultad con que nos encontramos a la hora de analizar el exilio español en República Dominicana corresponde a cifrar el número exacto de españoles que llegaron a la isla caribeña. Como se indica más arriba, las cifras barajadas por los historiadores van desde los pocos más de 3000 hasta más de $4000 .^{4}$

La primera expedición de refugiados españoles a República Dominicana hay que situarla antes de noviembre de 1939. Así lo atestigua un informe redactado por Juan Ruiz Olazarán, fechado en marzo de 1940, en el que, tras utilizar fuentes como la información facilitada por los funcionarios de la Compagnie Transatlantique Française para la llegada de los emigrados, la de otras agencias navieras para constatar el volumen de españoles que habían salido de la isla, así como encuestas personales, aporta los datos que se muestran en el cuadro 1 .

En los meses siguientes hubo otras expediciones que trasladaron, cuando menos, a más de 1000 personas. Juan Carlos Gibaja aporta, en una relación de las principales expediciones que llegaron a República Dominicana utilizando cantidades aproximadas de viajeros, dos entradas más en la isla durante los meses de abril y mayo del mismo año (véase cuadro 2).

Es decir, que según estos datos el número de españoles que arribaron a República Dominicana fue de poco más de 4000 . Pero hay que tener en cuenta que el exilio en esta isla no fue un exilio estable. Las duras condiciones de vida, como más adelante veremos, hicieron que la estancia de una amplia mayoría de los refu-

${ }^{4}$ Rubio, Emigración, 1977, p. 190, y Llorens, Exilio, 1976, p. 152. giados no se alargara durante mucho tiempo, convirtiéndose en un exilio de paso.

En efecto, la salida de los españoles de República Dominicana comenzó desde el mismo momento de su llegada. Así, en marzo de 1940 habían abandonado la isla 320 refugiados. A esta cantidad había que sumar dos expediciones que salieron a mediados del mismo mes con dirección a Venezuela y México. La primera llevaba a bordo 33 españoles, mientras que la segunda contaba con 30 refugiados. Es decir que, según el informe de Olazarán, ya en marzo de 1940 habían abandonado República Dominicana unos 383 españoles. ${ }^{5}$ En resumen, de los aproximadamente 4000 españoles que habían ido a parar a República Dominicana, tan sólo quedaban en la isla, a mediados de 1940 , poco más de 3600 .

Precisamente esta es la cifra que el ex ministro republicano Tomás y Piera recogía en un informe que, desde Santo Domingo, remitió a la delegación de la JARE en México en octubre de 1940. Aunque Tomás y Piera computaba esta cantidad como el total de los refugiados españoles llegados a la isla, seguramente no tuvo en cuenta a aquellos que habían llegado con antelación a las grandes expediciones: "En República Dominicana han entrado en las siete $u$ ocho expediciones de los barcos Cuba, Flandre y Lassalle unas 3600 personas aproximadamente." 6

'Carta de Juan Ruiz Olazarán desde Ciudad Trujillo, 17 de marzo de 1940, Archivo Fundación Indalecio Prieto (en adelante AFIP), fondo República Dominicana.

"Informe desde Santo Domingo de Tomás y Picra para la delegación de la JARE en México, 13 de octubre de 1940, Archivo del Ministerio de Asuntos Exteriores (en adelante AMAE), fondo JARE, signatur: M-269. 
Cuadro 1. Llegadas a República Dominicana hasta febrero de 1940

\begin{tabular}{llc} 
Barco & \multicolumn{1}{c}{ Fecha } & Núm. de refugiados \\
Varios & Anterior a noviembre de 1939 & 128 \\
Flandre & 7 de noviembre de 1939 & 279 \\
Cuba & 10 de noviembre de 1939 & 63 \\
La Salle & 19 de diciembre de 1939 & 770 \\
Cuba & 11 de enero de 1940 & 509 \\
Lassalle & 23 de febrero de 1940 & 733 \\
Total & & 2482
\end{tabular}

Fuentes: Carta de Juan Ruiz Olazarán desde Ciudad Trujillo, 17 de marzo de 1940, Archivo Fundación Indalecio Prieto (AFIP), fondo República Dominicana. Que ya había españoles exiliados en la isla antes de la primera expedición en el buque Flandre también queda recogido en Llorens, Memorias, 1975, p. 18.

Cuadro 2. Llegadas en los meses de abril y mayo de 1940

$\begin{array}{lcc}\text { Barco } & \text { Fecha } & \text { Núm. de refugiados } \\ \text { Cuba } & 22 \text { de abril de } 1940 & 1000 \\ \text { Lassalle } & \text { 16 de mayo de } 1940 & 540 \\ \text { Total } & & 1540\end{array}$

Fuente: Gibaja, Indalecio, 1995, p. 215.

En definitiva, podemos decir que la cifra de refugiados españoles que llegaron a República Dominicana rondó los 4000. Pero también tenemos que constatar que nunca hubo tal cantidad de refugiados en la isla, ya que el éxodo se inició, como hemos visto, prácticamente desde el mismo momento de la llegada.

En efecto, si en marzo de 1940 eran 383 los exiliados que habían abandonado el refugio dominicano, a finales de ese mismo año la cifra se disparaba a los 2000 , por lo que los españoles que permanecían en la isla alcanzaban una cantidad similar. ${ }^{7}$

${ }^{7}$ Carta de Tomás y Piera a la delegación de la JARE en México, 13 de octubre de 1940, AMAE, fondo JARE, signatura M-269.
Esta tendencia se mantuvo invariable a lo largo del tiempo. En consecuencia, en febrero de 1943 el número de refugiados que permanecían en República Dominicana fluctuaba, según un informe de la Comisión Administradora del Fondo de Auxilio a los Republicanos Españoles (CAFARE), entre 800 y $1000,{ }^{8}$ mientras que una vez terminada la guerra mundial, "el número de refugiados podía contarse, más que por centenares, por docenas".?

${ }^{8}$ Informe que envía la CAFARE al secretario de Relaciones Exteriores de México, 16 de marzo de 1943, Archivo de la Guerra Civil de Salamanca (en adelante AGCS), fondo Carlos Esplá, signatura 4.3/4762.

\footnotetext{
${ }^{9}$ Llorens, Exilio, 1976, p. 153.
} 
PROFESIONES Y OCUPACIÓN DE LOS REFUGIADOS EN REPÚBLICA DOMINICANA

Si ésta es la realidad sobre el volumen de españoles que se ubicaron en República Dominicana, no menos problemático es analizar los criterios que se aplicaron para seleccionar a los que partieron hacia estas latitudes.

El criterio sobre quiénes eran los españoles que debían emigrar al continente americano sufrió varios cambios con el paso del tiempo. En los primeros momentos hay que tener en cuenta que la responsabilidad de los embarques recayó sobre el SERE, el cual, como se recordará, estaba en manos del gobierno de Negrín. Este organismo favoreció a comunistas y filocomunistas a la hora de asignar una plaza en los barcos que partieron hacia el nuevo continente, en detrimento del resto de luchadores antifascistas españoles, a pesar de que había un supuesto pacto entre todas las organizaciones sobre el reparto de cuotas para embarcar hacia América.

El acuerdo señalaba que los marxistas, entre los que se incluía al PSOE y la UGT, tendrían el $55 \%$ de las plazas en los embarques; los libertarios, $22 \%$; el grupo republicano, donde se incluía a los partidos catalanes, $20 \%$, y a aquellos españoles que no estuvieran afiliados a ningún partido u organización sindical les correspondería 3 por ciento. ${ }^{10}$

Sin embargo, estas cuotas no fueron respetadas. ${ }^{11}$ Los responsables del SERE llevaron a cabo entrevistas con los exiliados

${ }^{10}$ Circular núm. 25 del Movimiento Libertario, agosto de 1939. Véase, Pla, Exilians, 1999, p. 174, y Rubio, Emigración, 1977, p. 137.

"Según Javier Rubio, los embarques fueron distribuidos de la siguiente manera: $78.8 \%$ por los mar- españoles que se encontraban en Francia con preguntas que, de no ser respondidas "correctamente", significaban su exclusión de las listas de embarque. ${ }^{12}$ La situación fue de tal grado que organizaciones como la libertaria emitieron una circular en la que ponían en aviso a sus militantes sobre cómo contestar a dichas preguntas para evitar, de esta forma, ser excluidos de los embarques. ${ }^{13}$

Por otro lado, hay que tener en cuenta que las listas con los nombres de los españoles que embarcaban con rumbo al Nuevo Mundo, no eran complementadas única y exclusivamente por los responsables españoles. La representación del gobierno mexicano en Francia también influyó en la confección de dichas listas. Así, tras la llegada de los primeros exiliados a México, $y$ ante las dificultades de las autoridades

xistas -de los cuales $33.55 \%$ pertenecían al Partido Comunista de España (PCE)-, 18.6\% por los republicanos y $6.6 \%$ por los anarquistas. Rubio, Emigración, 1977, pp. 185-186.

${ }^{12}$ Las preguntas podían hacer referencia a la responsabilidad que había tenido cada organización en la pérdida de la guerra civil o a la opinión que se tenía sobre el golpe de Casado. Véanse las entrevistas a Silvia Mistral y Ricardo Mestre. La primera realizada por Enriqueta Tuñón en el domicilio de la entrevistada en la ciudad de México durante los días 19, 22, 24 y 29 de febrero y $3,7,9,11,14,16,18,22$ y 24 de marzo de 1998. La segunda realizada por Enricue Sandoval los días 4,10 y 12 de marzo y $8,13,18,20$, 22,27 y 29 de abril y $2,4,6,11,13$ y 16 de mayo de 1988 en la ciudad de México, Archivo del Instituto Nacional de Antropología e Historia (en adelante AINAII) de México, fondo Archivo de la palabra, signatura $\mathrm{PHO} / 10 / 97$ y $\mathrm{PHO} / 10 / 99$ respectjvamente.

${ }^{13}$ Carta de la delegación del Consejo en Londres al Consejo General del Movimiento Libertario en París, 5 de junio de 1939, Archivo Fundación Anselmo Lorenzo (en adelante AFAL), fondo Federación Local de CNT en Inglaterra, signatura 1/2/1-67. 
mexicanas de alojar y dar trabajo a la masa de refugiados españoles, se paralizaba la puesta en marcha de nuevos embarques y se estudiaba un cambio de criterio en la selección de los exiliados. Bassols, representante de México en Francia, proponía, ya a finales de julio de 1939, un nuevo plan de evacuación que daba prioridad al exilio político sobre la idea primaria de colonización agraria. ${ }^{14}$

De todas formas, este criterio político, a la hora de hacer la selección de quienes deberían viajar a América, no parecía el más adecuado, como se pudo comprobar cuando los españoles llegaron al nuevo continente. De hecho, Indalecio Prieto, máximo responsable de la JARE en México, criticaba en un principio la forma en la que se estaba llevando a cabo dicha selección entre los refugiados que se encontraban en Francia. Para Prieto, la emigración basada en clasificaciones políticas constituía "un desastre", ya que en ningún lugar se necesitaban socialistas, comunistas o anarquistas, sino que en realidad lo que hacía falta eran agricultores, mecánicos, etc., es decir, que la emigración debía intentar coordinar las necesidades del país de acogida con la profesión de los emigrantes, lo que facilitaría la colocación de éstos en su nuevo lugar de residencia. A este criterio, Prieto añadía una segunda condición: "absoluta preferencia para los refugiados en campos de concentración, colocando entre ellos, en primerísima línea, a los mutilados de guerra. Reputamos sagradas e inconmovibles esas líneas generales". 15

${ }^{14}$ Véanse los artículos de Mateos, "Republicanos", 2002, pp. 103-128, y "Embajada”, 2003, pp. $541-560$.

${ }^{15}$ Carta de Indalecio Prieto a Luis Nicolau D'Olwer, 22 de enero de 1940, AFIP, fondo Luis Nicolau
Sin embargo, estos planteamientos fueron cambiando según los acontecimientos se precipitaban. La invasión nazi a Francia, y el peligro de las extradiciones a territorio español de aquellos dirigentes políticos que eran reclamados por el régimen de Franco, supuso un cambio importante en los planteamientos defendidos con anterioridad. Desde este momento, la delegación de la JARE en México puso especial énfasis en que fueran aquellos que habían desempeñado cargos de confianza en la República española los que tuvieran un trato de privilegio a la hora de ocupar un lugar en los barcos que zarpaban desde el país galo. Por otro lado, hay que constatar que también la JARE, a la hora de facilitar los pasajes, caería en el favoritismo de anteponer a sus correligionarios socialistas -junto con republicanos o nacionalistas catalanes- a los refugiados españoles de otras tendencias políticas.

En definitiva, los criterios para confeccionar las listas de embarque, en un primer momento, no tuvieron en cuenta la relación entre la profesión y las posibilidades de ganarse la vida que estas ocupaciones brindaban en los países de acogida. Esta situación implicó graves problemas de subsistencia para los exiliados españoles que, en más de una ocasión, sólo pudieron sobrevivir mediante las subvenciones que les asignaron los organismos de ayuda. Esta realidad supuso a su vez un grave quebranto económico para las arcas de dichos organismos, pues aparte de pagar los

D'Olwer. En otra carta entre los mismos interlocutores, con fecha 25 de enero de 1940, Prieto escribía: "Aquella sagrada preferencia que debemos a los mutilados de guerra, por encima de todos los políticos, cualquiera que sea su jerarquía." AFIP, fondo Luis $\mathrm{Ni}$ colau D'Olwer. 
pasajes tuvieron que seguir manteniendo a una masa de exiliados que no podía ganarse la vida con sus profesiones. Con estas premisas, no es extraño que Prieto hiciera la siguiente recomendación a la JARE en Francia: "Si han de venir personas a las que haya de socorrerse aquí, es preferible que permanezcan en Francia bajo el auxilio económico que la Junta pueda dispensarles."16

Un ejemplo de toda esta problemática es fácilmente reconocible en la situación que vivieron los exiliados españoles que se instalaron en República Dominicana. En la carta que Juan Ruiz Olazarán envió a Prieto en marzo de 1940, se añadía una clasificación de las profesiones de los 2466 exiliados españoles ${ }^{17}$ que, según su recuento, habían llegado hasta esa fecha a República Dominicana. De ellos, 925 correspondían a las esposas sin profesión y sus hijos, a los que incluyó bajo el encabezado de "sus labores". El resto, 1 541, se agrupa por sectores, como se muestra en el cuadro 3. Por otro lado, en la misma carta se hacía un recuento de aquellos que habían encontrado colocación, y que según su estimación ascendían a $265 .{ }^{18}$ En referencia a las mujeres y a los niños, ninguno logró colocarse, según la misma relación.

${ }^{16}$ Carta de Indalecio Prieto a Luis Nicolau D'Olwer, 22 de enero de 1940, AFIP, fondo Luis Nicolau D'Olwer.

17 Aunque Ruiz Olazarán escribe en la carta la cantidad de 2477 refugiados, la suma de las cifras arroja una cantidad de 2 466. Carta de Juan Ruiz Olazarán desde Ciudad Trujillo, 17 de marzo de 1940, AFIP, fondo República Dominicana.

${ }^{18}$ En relación con las colocaciones, Ruiz de Olazarán hace la precisión de que puede suceder "que la verdadera [profesión], en algunos casos, sea distinta; la de los colocados es la que actualmente desempeñan, aunque al llegar figuren con otra".
En resumen, podemos ver cómo entre los refugiados españoles que habían llegado a República Dominicana hasta marzo de 1940 había un importante predominio de aquellos que pertenecían al sector terciario, en concreto, más de $53 \%$, mientras que poco más de $33 \%$ estaba encuadrado en el secundario, y tan sólo $13.50 \%$ pertenecía al primario. ${ }^{19}$

Si comparamos estas cifras con las correspondientes a las profesiones de los refugiados que llegaron a México y con aquellos que se quedaron en Francia, podemos encontrar una apreciable similitud con el país americano e importantes diferencias con el europeo (véase cuadro 4).

Es verdaderamente llamativo comprobar cómo el país que menos desarrollo económico tenía de los tres recibió el porcentaje más bajo de refugiados pertenecientes al sector primario y, sin embargo, el más alto en el sector terciario. En el mismo sentido, el porcentaje de los pertenecientes al sector secundario es superior al de México, cuando la industria de este último estaba más avanzada que la del país caribeño.

Si tenemos en cuenta que la principal actividad de la población en República Dominicana era la agricultura, nos podemos dar una idea de las dificultades que tuvieron los españoles para encontrar trabajo. De hecho, según los datos de colocación que aparecen en el cuadro 3, podemos comprobar que tan sólo 265 de los 2466 , habían encontrado trabajo remunerado. Es decir, tan sólo $10.75 \%$ del total. En consecuencia, $89.25 \%$ de los refugiados

${ }^{19}$ Javier Rubio, sobre un estudio correspondiente a 400 fichas, aporta los siguientes porcentajes: sector primario, $5.2 \%$; sector secundario, $25.1 \%$, y sector terciario, 69.7\%. Rubio, Emigración, 1977, p. 235. 
Cuadro 3. Profesiones de los refugiados españoles en República Dominicana

$\begin{array}{lrccc}\text { Sector } & \text { Refugiados } & \text { Porcentaje } & \text { Colocados } & \text { Porcentaje } \\ \text { Primario } & 208 & 13.50 & 97 & 36.60 \\ \text { Secundario } & 511 & 33.16 & 24 & 9.06 \\ \text { Terciario } & 822 & 53.34 & 144 & 54.34 \\ \text { Total } & 1541 & 100 & 265 & 100\end{array}$

Fuente: Carta de Juan Ruiz Olazarán desde Ciudad Trujillo, 17 de marzo de 1940, AFIP, fondo República Dominicana.

Cuadro 4. Comparación de las profesiones de los españoles exiliados por sectores (porcentaje)

$\begin{array}{lccc} & \text { Primario } & \text { Secundario } & \text { Terciario } \\ \text { Francia } & 32.75 & 48.94 & 18.31 \\ \text { México } & 22.16 & 29.07 & 48.77 \\ \text { República Dominicana } & 13.50 & 33.16 & 54.34\end{array}$

Fuente: Los datos sobre México y Francia fueron obtenidos de Pla, Exilians, 1999, p. 168.

no tenía ningún ingreso salvo las subvenciones de los organismos de ayuda.

Corroborando lo dicho hasta el momento, podemos también apreciar cómo precisamente los agricultores fueron en términos absolutos -97 colocados, lo que representaba $36.60 \%$ de todos los que tenían empleo-, los refugiados que tuvieron más posibilidades de trabajo en su nuevo lugar de residencia. A este respecto, Vicente Llorens reconocía que "en la emigración, los agricultores, que eran los menos, fueron en todas partes los preferidos". ${ }^{20}$

${ }^{20}$ Llorens recoge en su libro cómo en la expedición del Flandre, de noviembre de 1939, en la que llegó con otros 278 exiliados a República Dominicana, tan sólo uno figuraba como agricultor. Llorens, Memorias, 1975, p. 41.
En definitiva, es evidente que los criterios para confeccionar las listas de embarques no estuvieron sujetos a las necesidades de los países de acogida ni se primó las posibilidades de trabajo y asentamiento de los españoles en dichos países. De ahí los graves problemas con los que se tuvo que enfrentar la emigración española en República Dominicana, donde parecía más que evidente que, como escribía Ruiz Olazarán, "sólo la agricultura ofrece soluciones para el empleo". ${ }^{21}$ Pero hasta esta aseveración iba a ser puesta en entredicho por la dura realidad.

${ }^{21}$ Carta de Juan Ruiz Olazarán descle Ciudad Trujillo, 17 de marzo de 1940, AFIP, fondo República Dominicana. 


\section{LOS ASENTAMIENTOS EN LAS COLONIAS AGRÍCOLAS Y OTRAS OCUPACIONES}

En el momento de la llegada de los refugiados españoles a República Dominicana, el gobierno de Trujillo procedió al acomodo de una parte de ellos en diferentes colonias de la periferia de la isla con la idea de que los recién llegados se ocuparan en actividades agrícolas. ${ }^{22}$

La Secretaría de Estado y Agricultura dominicana, de acuerdo con la Junta de Inmigración Española creada a tal efecto, proporcionó tierras, además de semillas y herramientas para el trabajo agrícola, a los exiliados españoles. La ayuda se completaba con materiales para la construcción de sus viviendas y un subsidio que percibirían durante los primeros seis meses, tiempo que se estimaba suficiente para poder emanciparse económicamente. Por su parte, los colonos estaban obligados a atender las tierras, los cultivos, la casa, etc., así como a ocuparse de la producción, consumo y venta de los productos agrícolas.

Sin embargo, la gran mayoría de los exiliados carecía de conocimientos acerca del trabajo en el campo, lo que, aunado a las duras condiciones de vida debido al clima y al terreno, supuso el abandono del medio rural de una buena parte de los españoles, y la búsqueda de trabajo y asentamiento tanto en la capital como en otras ciudades de la isla.

En agosto de 1940, la delegación de la JARE en México mandó a República Dominicana al ex ministro Tomás y Piera para tener información de primera mano

\footnotetext{
${ }^{22}$ Según Llorens, "los que vivieron en pueblos y zonas rurales pasaban del millar". Llorens, Memorias, 1975 , p. 39.
}

sobre la situación real de los refugiados españoles. Además de los informes proporcionados por el ex ministro, la JARE recibió una información especial sobre cada una de las ocho colonias en las que estaban ubicados los refugiados españoles y más de 300 informes personales de cabezas de familia instalados en la capital y en otras poblaciones de República Dominicana.

La delegación cifraba en 1600 los españoles que a principios de 1941 quedaban en la Dominicana. Unos 1000 vivían en núcleos urbanos, principalmente la capital, donde estaban ubicados unos 800 , de los cuales 366 eran cabezas de familia y 624 familiares. Aunque Tomás y Piera cifraba en unos 100 los que habían logrado encontrar buenos empleos en la universidad, en obras públicas, en el ejército o en la marina ${ }^{23}$ la delegación reconocía la falta de trabajo y la gran dificultad que tenía la inmensa mayoría a la hora de encontrar una colocación: "Su adaptación a industrias y comercios debe considerarse nula en absoluto, sin que existan por ahora posibilidades de mejorar." 24

Si ésta era la negra situación en las ciudades, la realidad de los que vivían de la agricultura no era mejor. La Secretaría de Agricultura del gobierno dominicano había concentrado a los españoles en ocho colonias agrícolas y siete grupos especiales. Las primeras tenían los nombres de Dajabón, Villa Trujillo, La Cumbre, Medina, Juan Herrera, El Llano, Constanza y Pedro

${ }^{23}$ Informe de Tomás y Piera desde Santo Domingo, fechado el 23 de octubre de 1940, AMAE, fondo JARE, signatura M-269.

${ }^{24}$ Memorándum de la delegación de la JARE sobre los exiliados en República Dominicana, AMAE, fondo JARE, signatura M-269. 
Sánchez, que contabilizaban un total de 559 refugiados, entre cabezas de familia y familiares. Los siete grupos especiales eran el Grupo de la Vega, el Grupo de Hato Mayor, Jarabacoa, Carretera Mella Km 17, Grupo de Jumunucú, Colonia Especial y otros colonos dispersos. En total, estos grupos contaban con 51 refugiados. Es decir, que el número total de refugiados españoles que a principios de 1941 estaba asentado en zonas agrícolas era de 610 , de los cuales 284 eran trabajadores agrícolas y el resto, 326, familiares. ${ }^{25}$

La puesta en marcha de las colonias agrícolas estuvo plagada de dificultades. Si el proyecto preveía que en seis meses los colonos se podrían independizar, porque en ese tiempo ya habrían recolectado una cosecha, la situación real distó mucho de estas previsiones. Por un lado, los colonos se quejaban de que las tierras, en el momento de la entrega, no estaban preparadas para el cultivo, y que la aportación de las semillas y herramientas se había realizado con retraso. Por otro lado, no hay que olvidar que la profesión de la mayoría de los españoles allí desplazados no era precisamente la agricultura, y que aquellos que habían sido campesinos en España se encontraban en un medio y con unos cultivos muy diferentes a los que estaban acostumbrados a trabajar.

A este respecto, hay que señalar que el cultivo casi único era el maní, de pobre rendimiento, mientras que otros cultivos más acordes con los conocimientos del campesinado español, como las patatas, las hortalizas o las leguminosas conllevaban una gran dificultad. El clima tropical y las condiciones del suelo eran otros elemen-

${ }^{25}$ Ibid., signatura M-269. tos fundamentales a tener en cuenta. El exceso de lluvias, las plagas y el ahogo de matas debido a una vegetación exuberante representaban condiciones que necesitaban un periodo más dilatado de adaptación.

En conclusión, la falta de conocimientos agrarios de una amplia mayoría de los refugiados españoles, la carencia de medios, las diferencias de cultivos y las condiciones edáficas y climáticas supusieron que, nada más iniciada la experiencia de las colonias agrícolas, éstas presentaran una situación alarmante:

La cosecha de papas y habichuelas se ha perdido totalmente por haberse hecho las siembras tardías y parte de la cosecha de habichuelas por habérselas comido los animales [...] En una palabra: la colonia carece de los implementos necesarios para continuar la rotación normal de los cultivos. Que esta carencia de instrumentos de trabajo -yuntas, arados, rastras, sembradoras, etc.- ha sido y es la causa principal de que los colonos firmantes no se hayan emancipado económicamente [...] Por otra parte, en esta zona no existe ninguna entidad industrial o de crédito a la que poder recurrir para hacer frente a las necesidades más apremiantes de la vida, pues algunos colonos carecen ya de todo medio para subsistir. ${ }^{26}$

Esta situación se repitió en todas las colonias agrícolas que se pusieron en funcionamiento. Así, en La Cumbre los colonos reconocían que "la colonia ha fracasado totalmente y el hambre se cierne ya sobre

${ }^{26}$ Carta firmada por los colonos españoles ubicados en El Llano, encabezada por Fidel Miró, dirigida a Rafael Leónidas Trujillo, presidente de República Dominicana, 17 de junio de 1940, AFIP, fondo República Dominicana. 
todos nosotros". ${ }^{27}$ En Pedro Sánchez los españoles se quejaban de la falta de los "medios más elementales para el cultivo de las tierras [...] que los asentados no son campesinos y que se trata de tierras que jamás han sido cultivadas". ${ }^{28}$ Además las condiciones de vida eran míseras. Las casas eran muy rudimentarias, hechas con tablones de madera y en la mayoría de los casos no disponían de luz eléctrica, porque las plantas que suministraban el alumbrado estaban "paradas por falta de gasolina y aceite", o el tractor no funcionaba por falta de combustible y la imposibilidad de los colonos de hacer frente a su sostenimiento. 29

En definitiva, que los proyectos de instalación y repoblación en las zonas agrícolas que había pretendido el gobierno de República Dominicana habían fracasado completamente. Los refugiados españoles intentaron abrirse camino en las ciudades pero, como hemos visto, la situación era también muy complicada. Así que la única posibilidad de subsistir, para muchos refugiados, consistió en volver a las colonias y vivir de los subsidios que aportaba la JARE. En resumen, que las colonias agrícolas se convirtieron en auténticos y simples refugios donde los españoles intentaron sobrevivir hasta que encontraran el medio de salir del infierno en el que se había convertido la isla dominicana.

${ }^{27}$ Carta de Ramón Solar, colono de La Cumbre, a Lucio Martínez Gil en México, 30 de junio de 1940, AMAE, fondo JARE, signatura M-269.

${ }^{28}$ Carta de Ruiz Olazarán a la delegación de la JARE en México, 9 de julio de 1940, AFIP, fondo República Dominicana.

29 Informe sobre las colonias agrícolas firmado por Luis Romero Solano con destino a la delegación de la JARE en México, 12 de diciembre de 1940, AMAE, fondo JARE, signatura M-268.

\section{LA JARE EN SANTO DOMINGO}

Las expediciones a República Dominicana fueron organizadas y subvencionadas por el SERE. Este organismo invirtió grandes cantidades en el transporte, así como en la instalación y el sostenimiento, a través de subsidios, de los refugiados españoles. ${ }^{30}$ Pero el SERE comenzó a tener problemas de dinero desde los primeros meses de 1940, lo que supuso la supresión de cualquier tipo de ayuda que, hasta ese momento, habían recibido los exiliados. Así, en febrero del mismo año, el gobierno dominicano intervino el depósito consignado por los refugiados españoles que habían llegado en el vapor La Salle -que ascendía a 28500 dólares-, ante la ausencia de los fondos que el SERE había ofrecido a las autoridades dominicanas. Esta cantidad se utilizó para la construcción de pabellones de madera, compra de mobiliario y una subvención de cinco dólares para la alimentación de los recién llegados que, de esta manera, aseguraba su estancia por dos meses. $^{31}$

Esta situación se volvió a repetir en julio de 1940 con la llegada a República Dominicana del vapor Cuba, que transportaba a unos 600 refugiados. Pero esta vez, ante la falta del depósito pertinente, el gobierno dominicano prohibió el desembarque de los españoles. Al igual que las expediciones anteriores, el SERE había organizado èste viaje, y a su delegación en México -el Comité Técnico de Ayuda a

30) Así lo reconoce Indalecio Prieto en una carta a Luis Nicolau D'Olwer de fecha 22 de enero de 1940, AFIP, fondo Luis Nicolau D'Olwer.

${ }^{31}$ Carta de Ruiz Olazarán desde Ciudad Trujillo a Indalecio Prieto, 17 de marzo de 1940. AFIP, fonclo República Dominicana. 
los Republicanos Españoles (CTARE)- 32 no le quedó más remedio que escribir una carta a la delegación de la JARE en la que, tras señalar la falta de recursos de la organización, solicitaba la ayuda económica de la Junta para solucionar el problema. $^{33}$

La JARE contestó inmediatamente de forma afirmativa. Prieto realizó unas gestiones ante el presidente de México, Lázaro Cárdenas, en las que se comprometía a pagar el transporte y el sostenimiento de los 600 españoles que se encontraban a bordo del Cuba. En consecuencia, por un lado la JARE pagó a la compañía naviera 24000 dólares como flete desde Ciudad Trujillo a Puerto México, y dejó una señal de 25000 dólares con la que aseguraba el desembarco en México. Por otro, el acuerdo alcanzado con el mandatario mexicano implicaba que la JARE se ocuparía del sostenimiento de los exiliados mientras no tuvieran trabajo y facilitaría los recursos necesarios para su asentamiento en las zonas dispuestas por el gobierno de México. Por último, Prieto se dirigió al CTARE para que ayudara a coordinar toda esta operación. Cada organización nombró un representante que se ocupó de realizar las ges-

32 Este Comité se constituyó el 13 de junio de 1939 con la llegada del buque Sinaia a Veracruz. Su misión era organizar la recepción y el asentamiento de los exiliados. El presidente fue José Puche, y colaboraron con él, entre otros, Gregorio Amador, Adolfo Vázquez Humasque, Joaquín Lozano, José Cordero, Luis Muñoz, Enrique del Castillo, Patricio González, Juan Guillén Guardiola, Ignacio Hidalgo de Cisneros, Amaro del Rosal, L. Almadén, P. Pastor de la Pisa, L. García Méndez, J. Armisen, M. Tejedor, J. Guillemón y L. Taracido. Véase Olaya, Gran, 1996, pp.129-130.

33 Acta núm. 89 de la delegación de la JARE en México, AGCs, fondo Carlos Esplá. tiones pertinentes. La JARE designó a José Andreu y el Comité a Joaquín Lozano. ${ }^{34}$

Desde este momento, la delegación de la JARE en México se ocupó de los españoles refugiados en República Dominicana ante la falta de recursos de la organización dirigida por José Puche.

La siguiente medida tomada por la JARE consistió en el nombramiento del ex ministro republicano José Tomás y Piera como delegado de la organización en República Dominicana. La primera misión del ex ministro fue trasladarse a este país y estudiar la situación real de los refugiados. ${ }^{35}$ La llegada del nuevo delegado levantó todo tipo de expectativas en la isla. Por un lado, para los propios españoles, que veían a Tomás y Piera como la persona que iba a poner remedio a todos los problemas que los acuciaban. Por otro, para los comerciantes, hosteleros, industriales... dominicanos que habían realizado préstamos a los refugiados y que ahora veían la posibilidad de recuperar su dinero. Y, también, para el gobierno de Trujillo, que pudo imaginar la posibilidad de una importante inversión de la JARE en su país. En concreto, Tomás y Piera llegó a señalar a las autoridades la posibilidad de crear un pueblo español en la isla con inversiones en agricultura, ganadería e industrias asociadas. ${ }^{36}$

Tras casi tres meses de estancia en la Dominicana, el delegado comunicaba a

${ }^{34}$ Acta núm. 94, 13 de julio de 1940, y acta núm. 95,14 de julio de 1940, de la delegación de la JARE en México, ibid.

${ }^{35}$ Acta núm. 114 de la delegación de la JARE en México, 17 de agosto de 1940, ibid.

${ }^{36}$ Informe de Ramón Solar a las ejecutivas del PSOE, UGT y Agrupación Socialista de México, 12 de marzo de 1941, AFIP, fondo República Dominicana. 


\section{SECUENCIA}

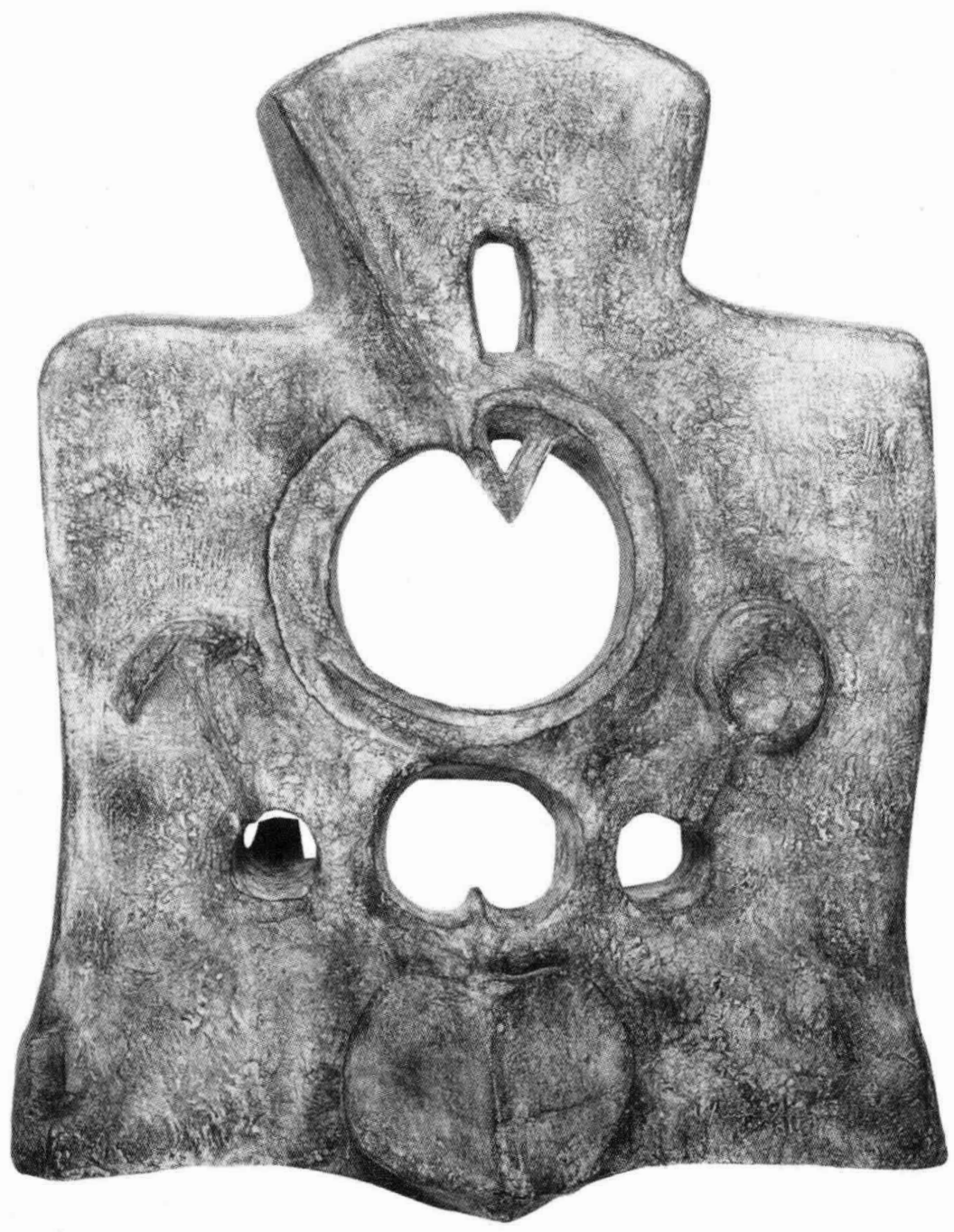


la JARE la cancelación de los créditos que los españoles habían solicitado, y señalaba que esta medida había "causado una buena impresión en todo el mundo: colonos, acreedores y gobierno". Según el nuevo delegado, se había recobrado la atmósfera de confianza en la isla. ${ }^{37}$

Sin embargo, los informes que redactó Tomás y Piera incidían en la difícil situación en la que se encontraban los españoles allí refugiados. El problema le parecía especialmente grave para aquellos que vivían en las colonias agrícolas, donde muchos se encontraban enfermos, principalmente palúdicos. Ante el alarmante deterioro de la salud de los exiliados, Tomás y Piera organizó, a principios de noviembre de 1940, un servicio médico farmacéutico provisional. ${ }^{38}$

A los pocos días llegaba la primera ayuda económica desde la capital mexicana para cubrir las necesidades más inmediatas. La cantidad enviada fue de 9000 dólares, de los cuales 5860 se emplearon en la liquidación de attasos y nuevos créditos para las colonias, y los 3200 restantes para atender hospitalizaciones, inválidos de guerra, enfermos graves y asistencias sociales en general. Al mismo tiempo, se realizaba la primera previsión de gastos, a la espera de tomar medidas definitivas. Las estimaciones preveían un gasto mensual de 7530 dólares, que se repartían de la siguiente forma: subsidio a las colonias agrícolas, 3 300; atenciones médico farma-

${ }^{37}$ Informe de Tomás y Piera a la delegación de la JARE en México, 7 de noviembre de 1940, AMAE, fondo JARE, signatura M-269.

${ }^{38}$ Informe de Tomás y Piera desde República Dominicana para la delegación de la JARE en México, 4 de noviembre de 1940, AMAE, fondo JARE, signatura M-269. céuticas y asistencia, 4000 ; sueldos, 180, y alquiler y correspondencia, $50 .{ }^{39}$

Terminada su misión, Tomás y Piera volvió a México. Antes propuso a la delegación de la JARE la formación de una comisión, con domicilio en Ciudad Trujillo, para atender a los refugiados españoles. La comisión estuvo compuesta por el doctor Jaime Roig Padró, Luis Romero Solana, Fernando Arisnea y Mariano Vives. Esta propuesta fue aprobada por la JARE, con la salvedad de que sus integrantes no debían considerarse como representantes de la JARE en República Dominicana, sino como colaboradores de Tomás y Piera, es decir, una delegación personal suya. Esta extraña salvedad se explica porque la JARE no quería ampliar el número de personas "fijas" que trabajaban para la organización. De ahí que se insistiera en que el dinero que los miembros de esta comisión iban a cobrar era una "gratificación por este servicio transitorio". 40

Pero estas reticencias no pudieron mantenerse por mucho tiempo. El incremento continuo de competencias de la comisión debido a la grave situación de los refugiados españoles en la isla, unido

${ }^{39}$ Carta de Prieto a Tomás y Piera, 5 de noviembre de 1940, y Memorándum sobre los exiliados en República Dominicana, ibid.

${ }^{40}$ Jaime Roig Padró, Luis Romero Solana y Fernando Arisnea cobraron, en un primer momento, 50 dólares al mes, y Mariano Vives, 30 . Por su parte, José Tomás y Piera quedó adscrito a la secretaría general de la delegación de la JARE en México para encargarse, principalmente, de los asuntos relacionados con República Dominicana. Su retribución fue de 300 pesos al mes. Acta núm. 175 de la delegación de la JARE en México, 2 de diciembre de 1940, AGCS, fondo Carlos Esplá, y Carta de José Tomás y Piera a Jaime Roig, 5 de diciembre de 1940, AMAE, fondo JARE, signatura M-268. 
a las quejas de algunos sectores afines al Partido Socialista que criticaban que el delegado Tomás y Piera no residiera en República Dominicana sino en México, ${ }^{41}$ supuso el reconocimiento de la comisión como representación oficial de la JARE. En su nueva composición, Jaime Roig ocupó el cargo de presidente, y era el responsable de la asistencia social para atender a los enfermos, inválidos, maternidad, etc.; como vocales estuvieron Luis Romero, encargado de las relaciones con las colonias, y Miguel Benavides. Por último, Fernando Arianea ocupó el puesto de secretario contador. La delegación prescindió de los servicios de Mariano Vives.

Esta delegación se rigió por las normas acordadas desde México. En general los responsables de la JARE en México pretendieron que la delegación en República Dominicana funcionara de forma colegiada para evitar, en lo posible, que las decisiones fueran resultado de criterios personales. En consecuencia, los acuerdos se tomaron con los votos del presidente y los dos vocales, y tenían plena efectividad cuando se produjeran por unanimidad y concerniesen a la concesión de socorros y distribución de los auxilios. Cuando las resoluciones no contaban con unanimidad, las opiniones de cada uno se elevaban a la delegación de la jare en México, que era quien tomaba la decisión final. ${ }^{42}$

41 Informe de Ramón Solar a las ejecutivas del PSOE, UGT y Agrupación Socialista de México, 12 de marzo de 1941, AFIP, fondo República Dominicana.

${ }^{42} \mathrm{La}$ asignación económica fue de 75 dólares para el presidente y 60 para los vocales y el secretario. Actas núms. 38 y 42 de la delegación de la JARE en México, 22 y 28 de abril de 1941 respectivamente, AGCS, fondo Carlos Esplá.
Desde un principio, la atención a los refugiados que se encontraban en las colonias agrícolas fue prioritaria. La delegación entendió que allí estaban los más necesitados, tanto por las duras condiciones de vida como por el alto número de enfermos. En primer lugar, la JARE concedió un donativo de cinco dólares a todas y cada una de las más de 600 personas que vivían en el medio rural. ${ }^{43}$ Pero el aumento continuo de refugiados que se acogían al régimen de colonias, porque no tenían otro modo de ganarse la vida', significó una disminución de la cantidad aportada. Así que el subsidio mensual se concretó en cinco dólares para los cabezas de familia y hombres solos y de en 3.5 dólares para cada familiar. ${ }^{44}$ De todas formas, como más adelante veremos, la partida que la JARE gastó en las colonias fue, en un principio, la más elevada del presupuesto mensual.

En cuanto al servicio médico farmacéutico, éste atendió, por un lado, a enfermos, hospitalizados, medicinas o alimentos especiales para niños. Por otro, la JARE consignó subsidios transitorios para mutilados, viudas y ancianos. Además se incluyó una cantidad para los médicos que atendían en las colonias y se hizo frente a socorros urgentes excepcionales, tales como gastos de entierro, partos o socorros personales transitorios. El servicio médico farmacéutico estaba dirigido por el doctor

${ }^{43}$ Carta de Tomás y Piera desde México a Jaime Roig en Ciudad Trujillo, 5 de diciembre de 1940, AMAE, fondo JARE, signatura M-268.

${ }^{44}$ Acta núm. 193 de la delegación de la JARE en México, 2 de enero de 1941, AGCs, fondo Carlos Esplá, y nota de servicio núm. 259 de la delegación de la JARE en México enviada a Tomás y Piera, 4 de enero de 1941, AMAE, fondo JARE, signatura M-269. 
Roig, aunque debía consultar con el resto de compañeros de la delegación cualquier asunto excepcional antes de tomar una decisión. La JARE exigía, en todo caso, que se pusiera especial cuidado en que las normas que regían este servicio se cumplieran con gran rigidez, al igual que se controlase las causas por las que se recibían las ayudas en previsión de fraudes. ${ }^{45}$

Las colonias agrícolas y el servicio médico farmacéutico fueron, en los primeros meses, las dos partidas en las que más gastó la delegación de la JARE en República Dominicana. Así, en los meses de febrero, marzo y abril de 1941 la propuesta de gasto que presentaba el delegado de la JARE en República Dominicana, que fue aprobada por la delegación en México, ascendía a las cantidades que se muestran en el cuadro 5.

Pero las duras condiciones de vida en República Dominicana supusieron cambios apreciables en los gastos. Como se puede comprobar en la liquidación de cuentas para los meses de septiembre y octubre de 1941 (véase cuadro 6).

Como se puede apreciar, los gastos en el servicio médico farmacéutico prácticamente se doblaron y superaron a las cantidades que se invertían en las colonias. Esta circunstancia se debía a que la salud de los españoles era cada día peor. En un informe que realizó el doctor Agustín Cortés, a mediados de 1942, se señalaba que era raro el español que trabajando en la agricultura no estaba afectado por el paludismo. Además, la escasa alimentación y su poco valor nutritivo implicaban una

45 Normas para el servicio médico farmacéutico en República Dominicana editadas por la delegación de la JARE en México, 9 de diciembre de 1940, AMAE, fondo JARE, signatura M-268. anemia casi generalizada, situación que se veía agravada por la fuerte desmoralización que afectaba a la inmensa mayoría de los refugiados españoles. ${ }^{46}$ De hecho, ya en el primer semestre de 1942 el servicio farmacéutico acaparaba, prácticamente, toda la ayuda que llegaba desde México. Sin embargo, este gasto había sufrido, en ese momento, una reducción considerable, en concreto rondaba tan sólo los 1000 dólares mensuales. ${ }^{47}$ Este cambio se debía a que la salida de la isla se había ido configurando como una prioridad para los españoles allí residentes.

En efecto, con las duras condiciones de vida reinantes en República Dominicana, no era de extrañar que la cuenta de viajes, que recogía los gastos de salida de los españoles de la isla, sufriera un incremento considerable. De hecho, en el balance de gastos que presentó la delegación de la JARE sobre las atenciones prestadas a los españoles residentes en República Dominicana durante el primer año, concretamente entre los meses de diciembre de 1940 y noviembre de 1941, el concepto de "pasajes y visados" era el más elevado de todos (véase cuadro 7).

Es decir, que traspasado a dólares -con un cambio aproximado de un dólar por seis pesos-, los gastos de la JARE en República Dominicana durante los primeros doce meses ascendieron a más de 204000 dólares, lo que suponía un gasto mensual medio de unos 17000 dólares. De ellos, la media mensual gastada en las colonias

\footnotetext{
${ }^{46}$ Informe médico del doctor Agustín Cortés a la delegación de la JARE en México, 7 de julio de 1942, AFIP, fondo República Dominicana.

${ }^{47}$ Así aparece en los gastos de la delegación en República Dominicana entre febrero y mayo de 1942, AMAE, fondo JARE, signatura M-274.
} 
Cuadro 5. Gastos de la Jare en República Dominicana de febrero a abril de 1941 en dólares

$\begin{array}{lccc}\text { Gasto } & \text { Febrero } & \text { Marzo } & \text { Abril } \\ \text { Médico-farmacéutico } & 1945 & 1945 & 2505 \\ \text { Colonias } & 4000 & 4000 & 3222 \\ \text { Total } & 5945 & 5945 & 5727\end{array}$

Fuente: AMAE, fondo JARE, signatura M-268.

Cuadro 6. Cuenta general para los meses de septiembre y octubre de 1941

$\begin{array}{lrr}\text { Gasto } & \text { Septiembre } & \text { Octubre } \\ \text { Médico-farmacéutico } & 4119.47 & 4758.75 \\ \text { Colonias } & 3521.90 & 3584.75 \\ \text { Viajes } & 2317.00 & 2312.00 \\ \text { Varios } & 541.63 & 482.13 \\ \text { Total } & 10500.00 & 11137.63\end{array}$

Fuente: AMAE, fondo JARE, signatura M-273.

Cuadro 7. Gastos de la JARE en República Dominicana entre diciembre de 1940 y noviembre de 1941 (en pesos mexicanos)

Atenciones a las colonias agrícolas

319841.41

Servicio médico farmacéutico

202510.20

Pasajes y visados

670792.30

Socorros y viajes procedentes de la Martinica a Santo Domingo

33645.30

Total

1226798.21

Fuente: AMAE, fondo JARE, signatura M-213.

rondaba los 4500 , mientras que en los gastos médicos farmacéuticos alcanzaban los 2800 dólares mensuales.

En mayo de 1942, Indalecio Prieto enviaba una carta a las autoridades dominicanas en la que hacía un balance de los gastos totales realizados por la JARE en Re- pública Dominicana y que según su contabilidad ascendían a 224125.80 dólares. A la vista de estas cantidades, Prieto ponía el acento en la importante aportación que la organización que él dirigía había realizado en la isla caribeña. El dirigente socialista aseguraba que los españoles allí refu- 
giados habían disfrutado de subsidios que no se daban en ninguna otra parte, por lo que se podían considerar "verdaderos privilegiados comparándolos con el resto de compatriotas diseminados por América". ${ }^{48}$

De todas formas, y a pesar de la aseveración de Prieto, los españoles optaban, cada vez en mayor medida, por salir de la isla. La JARE ayudó a varios centenares de ellos en los gastos de embarque y visados. De hecho, como se puede apreciar en el cuadro 7 , el total de la cuenta que recoge el gasto en viajes era superior a la suma de las cuentas correspondientes a las colonias y al servicio médico farmacéutico. $Y$ es que aunque se barajaron otras opciones, como a continuación veremos, cada vez parecía más evidente que la mejor opción para solucionar definitivamente el problema de los españoles era la salida de la islá.

\section{LA SALIDA DE REPÚBLICA DOMINICANA}

Como era evidente que la opción de asentar a los refugiados españoles en las colonias agrícolas concluyó con un rotundo fracaso, la delegación de la JARE en México barajó otras soluciones con las que intentó hacer factible el asentamiento definitivo de los exiliados españoles en República Dominicana. Entre ellas hay que destacar el intento de crear industrias. Las solicitudes para que el organismo de ayuda colaborase económicamente con dichas iniciativas fueron numerosas. En unos casos con la pretensión de montar industrias nuevas

\footnotetext{
${ }^{48}$ Carta de Indalecio Prieto a Max Manrique Uraña, enviado extraordinario y plenipotenciario de República Dominicana, 7 de mayo de 1942, AFIP, fondo República Dominicana.
}

de tipo familiar, en otros con la de ampliar o mejorar las ya existentes.

Todas las solicitudes eran tramitadas a través de la delegación en República Dominicana, que las remitía a la JARE en México. En la capital mexicana se hacía un estudio pormenorizado del costo, viabilidad, garantías, etc., del futuro negocio, y se emitía un informe. La dirección en México decidía, basándose en dicho informe, la concesión de los créditos para la puesta en marcha de estos negocios.

A principios de 1941 la delegación en México había recibido 132 peticiones para instalar industrias en la isla. Sin embargo la inmensa mayoría de ellas fue denegada. Las causas eran muy variadas; por un lado, estaba la repetición de industrias de la misma clase, como las instancias presentadas por tres relojeros u ocho carpinteros. La JARE entendía que no se podía incentivar la competencia entre los mismos españoles. Por otro, se consideraba que para la puesta en marcha de una industria no valía con la inversión inicial, sino que era necesario el mantenimiento de la ayuda hasta que la empresa comenzara a obtener beneficios, lo que podía suponer una inversión prolongada en el tiempo y, en consecuencia, muy costosa, por lo que se barajaron otras opciones;

La creación de industrias individuales está condenada al fracaso por cuanto es necesario una capacidad de resistencia que ninguno de los refugiados tiene [...] de hacer algo debe hacerse de una manera colectiva, señalando jornales suficientes a los obreros, tanto los del campo como los de la industria, y haciéndolos participar en los beneficios al objeto de estimular su producción [...] Sólo así, desde un punto de vista colectivo, socializante, si se quiere, en forma de cooperativa de 
producción y consumo, puede llegar a hacerse algo práctico y concreto en República Dominicana. ${ }^{49}$

En concreto, los informes se referían a "empresas colectivas" en las que estuviesen incluidas las colonias agrícolas, industrias de nueva creación y comercios. Estos proyectos se podían calificar de demagógicos por irreales. Ni República Dominicana tenía las condiciones económicas necesarias para que resultara interesante llevar a cabo estas inversiones ni la experiencia de los españoles afincados en las colonias agrícolas o residentes en las ciudades podía hacer pensar en la posible realización de estos planes tan utópicos. Porque, en definitiva, la única pretensión de la mayoría de españoles era abandonar la isla y buscar suerte en otro país americano, y además porque ésta era la única solución definitiva que invariablemente aparecía en todos los informes que se enviaban desde República Dominicana.

Pero la salida de la isla no fue nada fácil. Varias circunstancias influyeron en ello. Por un lado, los requisitos que imponían los países de acogida para admitir a más refugiados españoles. Por otro, las protestas que desde diferentes sectores políticos españoles exiliados se vertían sobre la forma en que se estaba articulando la ayuda desde la JARE y los criterios que se utilizaban para la confección de las listas de embarque. Además hay que mencionar la posición del gobierno dominicano que, si por un lado se sintió defraudado en gran medida por el abandono del país de buena parte de los españoles sin que se hubiera

\footnotetext{
${ }^{49}$ Informe sobre creación de industrias en República Dominicana, AMAE, fondo JARE, signatura M-269.
}

llevado a cabo la inversión que preveía en su país, por otro veía con gran inquietud la actividad política que una parte de estos refugiados llevaba a cabo, y que podía terminar colaborando con la oposición política interna contra la dictadura de Trujillo.

En relación con el primer punto, las salidas tuvieron como principal destino aquellos países en los que el costo del pasaje era más barato y donde ya se encontraban otros españoles exiliados, que les ayudarían a abrirse camino en los primeros momentos. Bajo estas premisas, la mayoría de ellos encontró acomodo en México y Venezuela, el resto se diseminó por otros países de América como Ecuador o $\mathrm{Pa}$ namá.

De todas formas, hay que tener en cuenta que la admisión de refugiados españoles era una cuestión que solía suscitar importantes reticencias en los países de acogida y, al mismo tiempo, requería el cumplimiento de una serie de premisas. Ambas situaciones fueron abordadas conjuntamente por la delegación de la JARE en México y por los propios interesados.

Así, las autoridades mexicanas no veían de buen grado el que llegaran a su país refugiados que ya hubieran encontrado acomodo en otro país americano. ${ }^{50} \mathrm{El}$ gobierno mexicano entendía que ya había admitido a un número considerable de exiliados españoles, y que las dificultades de éstos para encontrar trabajo en México podía desembocar en un grave problema social. A este respecto, el gobierno era pre-

${ }^{50} \mathrm{El}$ gobierno mexicano llegó a prohibir durante un tiempo la entráda de estos exiliados a México. Carta de Luis Romero desde Ciudad Trujillo a Ruiz Olazarán, 28 de marzo de 1941, AFIP, fondo República Dominicana. 
sionado por fuerzas conservadoras del país y por medios de comunicación afines para que pusiera fin a la admisión de españoles.

En estas circunstancias, la propia JARE, de acuerdo con las autoridades mexicanas, adoptó una serie de normas de obligado cumplimiento para aquellos que pretendían tener como destino el país azteca. En concreto, era necesario que el futuro refugiado presentara un contrato de trabajo o una garantía de que otras personas se comprometían a mantenerlos en México, con renuncia expresa a percibir subsidio o ayuda extraordinaria de la JARE. Además, se quería evitar la aglomeración de los españoles refugiados en la capital mexicana, según requerimiento de las autoridades, por lo que la JARE se comprometía a gestionar los visados y pagar el viaje hasta México a aquellos que tuvieran un grave problema de salud, con la condición de que aceptasen el acuerdo que la delegación había alcanzado con la Secretaría de Gobernación de México. Según éste, los refugiados tendrían "una residencia de clima sano, fuera del Distrito Federal, a donde se les trasladará en barco, ofreciéndose la JARE a mantenerlos durante un periodo de dos o tres meses".5I

A pesar de todo, la delegación de la JARE en México quiso atender a los refugiados que llegaban de República Dominicana con el mismo criterio que había puesto en marcha en otras expediciones anteriores, y acordó el pago de una quincena adelantada y otra en concepto de donativo extraordinario a razón de 1.50 pesos diarios para los cabezas de familia y 0.90 para los familiares. Estas cantidades se mantendrían por un espacio de tres meses.

${ }^{51}$ Nota de servicio núm. 259,4 de enero de 1941, AGCS, fondo Carlos Esplá, signatura 3.3c/2996.
Por otro lado, la JARE gestionó la residencia para los recién llegados en el estado de Michoacán, aplicándoles los mismos beneficios que a los españoles que ya se encontraban allí y habían aceptado fijar su residencia fuera de México capital. Por último, la JARE se hizo cargo del importe del viaje en tercera clase hasta el lugar de destino. ${ }^{52}$

Pero además de todos estos requisitos, las autoridades mexicanas obligaban a la delegación de la JARE a responsabilizarse de la honorabilidad y confianza de las personas que eran seleccionadas, por lo que la JARE insistía una y otra vez en que las listas con los refugiados que se presentaban ante las autoridades se confeccionaban "después de un escrupuloso examen de sus antecedentes y comprobando su buena conducta". 53

Precisamente esta selección dio lugar a importantes enfrentamientos entre las diferentes fuerzas políticas españolas exiliadas que, en más de una ocasión, fueron incapaces de solucionar el problema de forma interna y buscaron la mediación de los gobiernos de los países de acogida.

En efecto, las críticas a la confección de las listas llegaron desde todos los grupos políticos. Así, desde República Dominicana, los propios socialistas realizaban informes para sus organizaciones afines en México en los cuales se ponía especial énfasis en denunciar que los pasajes que estaba pagando la JARE para salir de la isla recaían en mayor medida en "individuos

${ }^{52}$ Acta núm. 197, 8 de enero de 1941, AGCS, fondo Carlos Esplá.

${ }^{53}$ Cartas de la delegación de la JARE en México al subsecretario de Gobernación, 20 de marzo de 1941 y 1 de octubre del mismo año, AMAE, fondo JARE, signatura $\mathrm{M}-270$. 
comunistas e indeseables", en detrimento de los socialistas, quienes, según estas fuentes, estaban siendo marginados. ${ }^{54}$ Por su parte, los libertarios afincados en México lanzaban duros ataques contra las dos principales organizaciones de ayuda a los exiliados, el SERE y la JARE, y su principales dirigentes, Negrín y Prieto, a quienes acusaban de despilfarro de los fondos republicanos y de la marginación de la que los militantes libertarios estaban siendo objeto en las listas de embarque. ${ }^{55} \mathrm{Y}$, cómo no, las críticas eran muy duras desde agrupaciones de exiliados en República Dominicana en las que la presencia comunista era importante, como sucedió con la Comisión de Refugiados Españoles, que envió una carta a las autoridades dominicanas en la que acusaba a la delegación de la JARE de una supuesta reducción de las subvenciones y un importante favoritismo político con sus correligionarios. ${ }^{56}$

Todas estas críticas fueron atendidas de forma diferente por la delegación de la jare en México. Por un lado, Prieto negó

${ }^{54}$ Informe de Ramón Solar a las comisiones ejecutivas del PSOE, UGT y Agrupación Socialista en México, 12 de marzo de 1941, AFIP, fondo República Dominicana. En términos parecidos se expresa Juan Muñoz Nevado en una carta a Indalecio Prieto de 21 de marzo de 1941, ibid.

${ }^{55}$ Véase España en el Exilio, núm. 1, 19 de julio de 1941, ciudad de México, en el Archivo Biblioteca Social Reconstruir (ABSR), México, D. F.

${ }^{56}$ Esta comisión envió diferentes cartas, firmadas por F. Dorado Martín, Ramón Costa Jou y Antonio Ordovás, en las que hacía especial hincapié en estas circunstancias, una a la delegación de la JARE en México, de 16 de abril de 1942; otra al secretario de Estado de lo Interior y Policía de República Dominicana, con fecha 30 de marzo de 1942. La primera en AFIP, fondo República Dominicana; la segunda en AGCS, fondo Carlos Esplá, signatura 3.5/4042. reiteradamente ante las autoridades dominicanas todas las acusaciones de las que era objeto por parte de libertarios y comunistas, ${ }^{57}$ por el otro, tranquilizó a sus compañeros de partido que se encontraban en la isla, haciéndoles ver que cualquier acuerdo que fuera tomado por la delegación en República Dominicana tendría que ser por unanimidad. En caso contrario, es decir, cuando hubiera discrepancia de alguno de sus miembros, sería la delegación en México la que decidiría. Prieto concluía subrayando que "nada, absolutamente nada podrá hacerse sin la aquiescencia del representante socialista". ${ }^{58}$

Lo cierto es que el control del PSOE en las listas de embarque fue evidente. Así lo demuestra el informe emitido por la delegación de la JARE sobre el expediente abierto a cada exiliado que pidió la salida de República Dominicana para su entrada en México en el periodo comprendido entre mediados de 1941 y marzo de 1942 (véase cuadro 8).

Como se puede apreciar, centrando el análisis en las principales formaciones políticas, socialistas, republicanas, libertarias y comunistas, las dos primeras salieron muy beneficiados en el reparto de las plazas para el embarque. Así, mientras los socialistas recibieron un informe favorable para $88 \%$ de sus solicitudes y los republicanos para $80 \%$, los libertarios se tuvieron que conformar con $46 \%$ y los comunistas no alcanzaron ni $2 \%$. Por otra parte, de las 387 solicitudes recibidas en total, la

${ }^{57}$ Carta de Prieto a Max Henríquez, enviado extraordinario y plenipotenciario de República Dominicana, 7 de mayo de 1942, AGCS, fondo Carlos Esplá, signatura 3.5/4042.

${ }^{58}$ Carta de Indalecio Prieto a Ramón Soler, 28 de abril de 1941, AFIP, fondo República Dominicana. 
Cuadro 8. Informe de salidas de República Dominicana, mediados de 1941 a marzo de 1942

$\begin{array}{lcccc}\text { Organización } & \text { Cabezas de familia } & \text { Informes favorables } & \text { Informes desfavorables } & \text { Dudosos } \\ \text { PSOE-UGT } & 136 & 120 & 11 & 5 \\ \text { Republicanos } & 49 & 39 & 5 & 5 \\ \text { CNT } & 60 & 28 & 13 & 19 \\ \text { PCE } & 54 & 1 & 49 & 4 \\ \text { PSUC } & 8 & - & 6 & 2 \\ \text { POUM } & 1 & 1 & - & - \\ \text { JSU } & 2 & 1 & 1 & - \\ \text { ERC } & 10 & 9 & 1 & - \\ \text { EV } & 1 & 1 & - & - \\ \text { MSI } & 1 & 1 & - & - \\ \text { Sin partido } & 37 & 23 & 7 & 7 \\ \text { Partido dudoso } & 28 & 6 & 16 & 6 \\ \text { Totales } & 387 & 230 & 109 & 48\end{array}$

Fuente: AMAE, fondo JARE, signatura M-270.

delegación de la JARE concedió un informe favorable a 230 , de ellas, $52 \%$ correspondía a los socialistas, $17 \%$ a los republicanos, $12 \%$ a los libertarios y un insignificante $0.4 \%$ a los comunistas.

Ante estas cifras, que son suficientemente elocuentes, no es de extrañar que las quejas de aquellos que fueron marginados se expresaran, en la mayoría de los casos, a través de cartas que tuvieron como destinatarios a la propia delegación o a las autoridades de los países de acogida. En otros casos, los menos, refugiados que no habían sido aceptados para el embarque decidieron llevar a cabo acciones de fuerza, como la protagonizada por un grupo de libertarios que ante lo angustioso de su situación presionó y amenazó a los miembros de la delegación de la JARE en Ciudad Trujillo para que les diera una cantidad de dinero y así poder escapar de la isla en una embarcación. Estos "trabajadores de la "pipa", como los denominaba la delegación en República Dominicana, estaban considerados como no gratos por las autoridades dominicanas, por lo que también éstas colaboraron en su salida:

Era tanto el deseo de perder de vista a los interfectos que, quien podía hacerlo me comunicó que se pondría en libertad a los detenidos, y no sólo se tendría una tolerancia para la salida clandestina sino que los guardacostas de servicio les observarían para que pudieran llegar a su destino sin grandes peligros. $^{59}$

Hay que tener en cuenta que el régimen dominicano estaba vigilante por todo lo que pudiera desembocar en "alteraciones del orden público" y que implicara una

${ }^{59}$ Carta de la delegación de la JARE en Santo Domingo a Indalecio Prieto, 10 de mayo de 1941, ibid. 
desestabilización de la dictadura impuesta por Trujillo. A este respecto, los contactos entre las autoridades dominicanas y la delegación de la JARE en la isla eran continuos. En mayo de 1941 el general García, secretario de Estado de lo Interior y Policía, hizo llegar su preocupación a Jaime Roig por la actitud de los refugiados que realizaban propaganda de carácter político. El general llegó a amenazar, durante la entrevista, con abrir campos de concentración o recurrir a las deportaciones. El militar dominicano citaba concretamente a los comunistas españoles como los principales alborotadores políticos.

Roig reconocía que la actividad que estaba llevando a cabo el Partido Comunista era importante. Los comunistas instalados en República Dominicana editaban folletos, realizaban conferencias en locales tales como teatros y estaban ampliando sus contactos con personas influyentes, en muchos casos enemigos de Trujillo. ${ }^{60} \mathrm{La}$ labor de los comunistas se completaba con la captación de militantes de otras organizaciones españolas que los ayudaran a poner en marcha alianzas con el resto de organizaciones en el exilio. Los comunistas pretendían, de este modo, retomar la unidad de acción de las fuerzas españolas y, al mismo tiempo, salir del aislamiento al que estaban sometidos. ${ }^{61}$

${ }^{60}$ Carta de Jaime Roig desde República Dominicana a Indalecio Prieto, 15 de mayo de 1941, ibid.

${ }^{61}$ A mediados de 1942 las Juventudes Libertarias $y$ las Juventudes Socialistas Unificadas firmaton un manifiesto en Ciudad Trujillo en el que llamaban a la unidad de acción de las fuerzas exiliadas españolas. Algunos de los firmantes libertarios, como Serafín Aliaga o Antonio Ordovás, terminaron militando en las filas comunistas. Solidaridad Obrera, núm. 5, junio de 1942, ciudad de México, en Archivo del Ateneo Español de México (AAEM), México D. F.
La delegación de la JARE intentaba neutralizar todo este malestar de las autoridades dominicanas a través de continuas promesas sobre la posibilidad de "ayudar a algunas pequeñas industrias a que se establecieran", e intentando convencerlas de que la mayoría de los refugiados que salían de la isla lo hacían o porque no encajaban por sus profesiones o por motivos de salud o familiares. ${ }^{62}$

Sin embargo, la policía dominicana presionaba a la delegación de la JARE en Ciudad Trujillo para que ciertos elementos "indeseables" fueran incluidos en las listas de embarque con destino a México, cuestión a la que la delegación se oponía. La situación llegó a tal punto que cuando se iba a proceder al embarque, en el buque dominicano Presidente Trujillo, de unas decenas de refugiados que habían permitido las autoridades mexicanas, el gobierno dominicano pretendió hacer embarcar por la fuerza a varias decenas de refugiados cuya entrada en México no estaba autorizada. Los representantes de la JARE, Luis Romero, Fernando Arisnea y Miguel Benavides, se opusieron, por lo que fueron detenidos e ingresaron en prisión. Los dos primeros fueron expulsados del país, mientras que el tercero fue puesto en libertad a los pocos días. ${ }^{63}$ La delegación de la JARE en México entendió esta situación como que las autoridades dominicanas se oponían a que su representación en Ciudad Trujillo continuara con su trabajo, por lo

${ }^{62}$ Carta de Jaime Roig desde República Dominicana a Indalecio Prieto, 15 de mayo de 1941, AFlP, fondo República Dominicana.

${ }^{63}$ Carta de la delegación de la JARE en México a Ernesto Hidalgo, oficial mayor de Relaciones Exteriores de México, 27 de febrero de 1942, AGCs, fondo Carlos Esplá, signatura 3.5/4031-b. 
que decidió sacar de la isla al resto de sus miembros.

Este era el fin de la representación de la JARE en República Dominicana, pero no el fin de las ayudas que siguieron llegando a la isla. La delegación en México, por un lado, solicitó al ministro de México en la Dominicana que se hiciera cargo provisionalmente de los documentos y enseres de la oficina, $y$, por otro, mantuvo el servicio médico farmacéutico y continuó enviando el dinero de los subsidios. Por último, los contactos con las autoridades dominicanas se mantuvieron, pero ya desde la aceptación, por ambas partes, de que el mejor remedio para los españoles que no tuvieran trabajo era el traslado a otros países americanos.

Pero la salida de República Dominicana continuó siendo tremendamente complicada. Ya no sólo por las reticencias de las autoridades mexicanas para autorizar la entrada de residentes españoles en otras repúblicas americanas, sino por los problemas de transporte que la segunda guerra mundial imponía. En efecto, el servicio marítimo entre Cuba, lugar de obligado tránsito, y México estaba interrumpido. El servicio aéreo era el único que funcionaba, aunque con grandes restricciones debido a la militarización que el gobierno de Estados Unidos había impuesto a la compañía Panamerican. Con esta situación, la JARE intentó desviar y, por lo tanto, facilitó el transporte a Panamá, lugar donde según los informes había más posibilidades de trabajo y el tráfico aéreo no estaba interrumpido. La JARE se comprometió a abonar el importe de los pasajes marítimos más gastos de documentación, en total unos 100 dólares por persona. Para aquellos que tuvieran la posibilidad de ir a otro país, la JARE les ayudaría en la misma cuantía que lo estipulado para Panamá. ${ }^{64}$

En definitiva, las ayudas por parte de la JARE a los refugiados españoles en República Dominicana se mantuvieron hasta la desaparición de la organización dirigida por Indalecio Prieto. Ésta tuvo lugar a los pocos meses, concretamente en noviembre de 1942, fecha en la que el gobierno mexicano intervino la JARE y constituyó la Comisión Administradora del Fondo de Auxilio a los Republicanos Españoles (CAFARE), controlada por las autoridades mexicanas.

Cuando esta Comisión comenzó su funcionamiento, el número de españoles refugiados en República Dominicana rondaba los 1000 . De ellos, una tercera parte tenía resuelta su situación económica. Un número alterno de españoles pasaba de tener trabajo a estar en el paro y, por lo tanto, con ingresos muy inseguros que hacían imprescindible el mantenimiento de las ayudas que hasta ese momento enviaba la JARE. Por último, más de la mitad del total, es decir unas 500 personas, no tenía otro ingreso que el subsidio que llegaba desde México; eran las viudas, los ancianos, los inválidos de guerra y los enfermos graves incapacitados para cualquier tipo de trabajo. ${ }^{55}$

${ }^{64}$ Acta núm. 266 de la delegación de la JARE en México, 11 de septiembre de 1942, AGCS, fondo Carlos Esplá.

${ }^{65}$ Informe realizado por diferentes partidos y sindicatos españoles desde Ciudad Trujillo enviado a la CAFARE, 3 de febrero de 1943, AFIP, fondo República Dominicana. 


\section{CONCLUSIONES}

La llegada de exiliados españoles a República Dominicana comenzó con anterioridad a noviembre de 1939. El volumen total de españoles que tuvieron como destino la isla caribeña alcanzó la cifra de 4000 . Aunque nunca hubo allí tal número de españoles exiliados, ya que prácticamente desde el mismo momento de su llegada hubo grupos de refugiados que abandonaron la Dominicana en busca de un destino mejor.

La adaptación a las condiciones de la vida en la isla fue muy complicada, tanto por la situación económica y social del país, como por la experiencia profesional de los españoles. Los criterios de selección para embarcar con destino a América no se realizaron basándose en las condiciones de los países de acogida, sino que fueron preferentemente políticos. Esta situación supuso un grave problema a la hora de conseguir que el exilio en la Dominicana fuera estable. En consecuencia, las pretensiones del gobierno de Trujillo de instalar a los españoles en colonias agrícolas fue un completo fracaso. Las enfermedades de los que trabajaban en el campo y las escasas posibilidades de encontrar un empleo a aquellos que vivían en las ciudades, supuso que la inmensa mayoría de los españoles sobreviviera gracias a los subsidios que aportaban las organizaciones de ayuda constituidas por los republicanos españoles.

Aunque las expediciones con destino a República Dominicana fueron subvencionadas por el SERE, ya a mediados de 1940 esta organización no contaba con fondos para seguir manteniendo a los allí desplazados. Desde este momento, la JARE se hizo cargo de la atención y ayuda a los re- fugiados españoles. La constitución de un servicio médico farmacéutico y el establecimiento de subsidios para los más necesitados o para los colonos que vivían en condiciones míseras, fueron algunas de las iniciativas que puso en marcha la organización que dirigió Indalecio Prieto desde México.

Pero como el exilio definitivo en República Dominicana se había mostrado imposible para la mayoría de los españoles, la JARE tuvo que invertir fuertes cantidades de dinero en pasajes y visados para sacarlos de la isla. De los más de 200000 dólares estadunidenses que la organización de ayuda gastó en los españoles exiliados en la Dominicana durante su primer año de actividad, más de la mitad correspondió a los gastos de embarque.

La actuación de la JARE en la isla caribeña no estuvo exenta de polémica. Las críticas que recayeron sobre esta organización de ayuda tuvieron como base tanto el volumen de los subsidios como la confección de las listas de embarque. Si por un lado hay que reconocer que el gasto que realizó la JARE en la Dominicana fue muy importante en relación con el número de españoles allí residentes, por otro, no es menos cierto que tanto socialistas como republicanos se vieron beneficiados a la hora de obtener un pasaje en los barcos que partían de la isla.

La JARE también tuvo problemas con las autoridades dominicanas. El gobierno del dictador Trujillo se sintió defraudado -y hasta cierto punto engañado- por el abandono de los españoles del país y, en consecuencia, por la desaparición de una inversión en la que habían puesto grandes esperanzas. Además, la importante actividad política de los comunistas españoles residentes en la isla preocupaba a las au- 
toridades dominicanas. Las presiones para que la JARE sacara de allí a aquellos que el gobierno de Trujillo tachaba de "indeseables", supuso el enfrentamiento con la representación de la Junta en la isla y su consiguiente desaparición.

A pesar de todo, la JARE siguió manteniendo las ayudas a los españoles allí exiliados hasta que, en noviembre de 1942, las autoridades mexicanas decidieron la incautación de sus bienes.

\section{FUENTES CONSULTADAS}

Archivos

AAEM Archivo del Ateneo Español de México. ABSR Archivo Biblioteca Social Reconstruir. AFAL Archivo Fundación Anselmo Lorenzo. AFIP Archivo Fundación Indalecio Prieto.

AGCS Archivo de la Guerra Civil de Salamanca.

AINAH Archivo del Instituto Nacional de Antropología e Historia de México.

AMAE Archivo del Ministerio de Asuntos Exteriores.

\section{Hemerografia}

-España en el exilio, 1941.

-Solidaridad Obrera, 1942.

\section{Bibliografía}

-Gibaja, José Carlos, Indalecio Prieto y el socialismo español, Pablo Iglesias, Madrid, 1995.

-Lida, Clara, Una inmigración privilegiada: comerciantes, empresarios y profesionales españoles en México en los siglos XIX y XX, Alianza Editorial, Madrid, 1994.

- Inmigración y exilio: reflexiones sobre el caso español, Siglo XXI, México, 1997.

-Llorens, Vicente, Memorias de una emigración. Santo Domingo, 1939-1945, Ariel, Madrid, 1975. , El exilio español de 1939. La emigración republicana de 1939, Taurus, Madrid, 1976.

-Mateos, Abdón, "Los republicanos españoles en el México cardenista”, Ayer, núm. 47, 2002, Madrid, pp. 103-128.

—, "La 'Embajada oficiosa' de Indalecio Prieto en México durante la presidencia de Lázaro Cárdenas, 1939-1940", Revista de Indias, núm. 228, mayo-agosto de 2003, Madrid, pp. $541-560$.

-Olaya, Francisco, La gran estafa: Negrín. Prieto y el patrimonio español, Ediciones Libertarias, Madrid, 1996.

-Pla, Dolores, Els exilians catalans, México, INAH, 1999.

-Rubio, Javier, La emigración de la guerra civil de 1936-1939, San Martín, Madrid, 1977. 